\title{
State space approach with fem for the determination of structural behaviour of composite plates
}

DOI:

10.1108/IJSI-01-2016-0002

\section{Document Version}

Accepted author manuscript

Link to publication record in Manchester Research Explorer

\section{Citation for published version (APA):}

Albostami, A., Wu, Z-J., \& Zou, Z. (2017). State space approach with fem for the determination of structural behaviour of composite plates. International Journal of Structural Integrity, 8(4), [ 1757-9864].

https://doi.org/10.1108/lJSI-01-2016-0002

\section{Published in:}

International Journal of Structural Integrity

\section{Citing this paper}

Please note that where the full-text provided on Manchester Research Explorer is the Author Accepted Manuscript or Proof version this may differ from the final Published version. If citing, it is advised that you check and use the publisher's definitive version.

\section{General rights}

Copyright and moral rights for the publications made accessible in the Research Explorer are retained by the authors and/or other copyright owners and it is a condition of accessing publications that users recognise and abide by the legal requirements associated with these rights.

\section{Takedown policy}

If you believe that this document breaches copyright please refer to the University of Manchester's Takedown Procedures [http://man.ac.uk/04Y6Bo] or contact uml.scholarlycommunications@manchester.ac.uk providing relevant details, so we can investigate your claim.

\section{OPEN ACCESS}




\section{Emerald International Journal}

\section{STATE SPACE APPROACH WITH FEM FOR THE DETERMINATION OF STRUCTURAL BEHAVIOUR OF COMPOSITE PLATES}

\begin{tabular}{|r|l|}
\hline Journal: & International Journal of Structural Integrity \\
\hline Manuscript ID & IJSI-01-2016-0002.R1 \\
\hline Manuscript Type: & Research Paper \\
\hline Keywords: & $\begin{array}{l}\text { State space approach, Finite element method, Neutral plane, Composite } \\
\text { plate }\end{array}$ \\
\hline \multicolumn{2}{|l}{} \\
\hline
\end{tabular}

SCHOLARONE $^{\text {IM }}$

Manuscripts 


\title{
STATE SPACE APPROACH WITH FEM FOR THE DETERMINATION OF STRUCTURAL BEHAVIOUR OF COMPOSITE PLATES
}

\begin{abstract}
In this paper, state space approach (SSA) and finite element method (FEM) are used for the determination of structural behaviour of simply supported orthotropic composite plates under different types of loading. The numerical results from a finite element model developed in ABAQUS are checked with those obtained by using SSA. The effect of the plate thickness on displacements and stresses is described quantitatively. It is found that the neutral plane (N.P.) of the plate, identified according to the values of the in-plane stresses through the thickness direction, is shifted away from the middle plane. Further investigation shows that the position of the N.P. is loading-dependant.
\end{abstract}

Keywords: State space approach, Finite element method, Composite plate, Neutral plane.

\section{Introduction}

The increasing demand on the structures made of the composite materials in various high performance applications led to the development of new methods that are suitable for the analysis and study of the structural and mechanical behaviour of the structures (Ye et al., 2004).

According to Reddy (2004) and Ghugal and Shimpi (2002), there are many approaches that were used for the analysis of the composite plates including classical plate theory (CPT) and various $2 \mathrm{D}$ shear deformation plate theories. The CPT was proposed by Kirchhoff (Kirchhoff, 1850). Kirchhoff plate hypothesis is a generalisation of the plane section assumption in the beam theory. Since CPT has several assumptions such as neglecting the normal strain through the thickness direction of a plate, together with the application of inconsistent plane stress constitutive relations under plane strain assumption, the precision of the theory reduces considerably as the increase of the plate thickness (Pagano 1987, Reddy 2004 and Han 2014). As the transverse normal stresses affect damage progression in characteristic failure modes like delamination (Rolfes et al., 1998) it is playing a very important role for the behaviour of composite plates. Such 2D method like CPT, however, has neglected this very important factor.

In order to overcome the limitations of the CPT, several modified 2D plate theories were proposed by different researchers in 1940's to 1950's. For example, to analyse two-dimensional plate structures, Reissner (1945) assumed shear stress distribution through the thickness of the plate in 1945. Reissner's theory takes into account the shear deformation and the transverse normal stresses. It is considered as a stress based shear deformable plate theory. In 1951, Mindlin proposed a displacement field through the plate thickness to account for the effect of shear deformation. Mindlin's (displacement-based) and Reissner's theories are today classified as the first order shear deformation theory (FSDT) as they actually lead a linear variation of the displacements through the plate thickness (Rashed, 2000). The most important feature of the plate theories with shear deformation is that they can be used to analyse both thin and mid-thick plates. The FSDT extends some kinematics assumptions in the CPT by assuming constant transverse shear strains through the thickness direction. It hence follows that the transverse shear stress will also be constant. To minimize the structural response difference caused by the real stress distribution and the assumed constant shear distribution, it has had to introduce the shear correction factors. Such factors are often sought resulting from the linear interpolation of the displacement field in the 
thickness direction of the plate (Kreja, 2011) and they depend on the geometry of the plate, loading and boundary conditions (Reddy, 2004). Obviously, the accuracy of the results mainly depends on the shear correction factor (Han, 2014).

To avoid such indeterminacy and in order to analyse and calculate the transverse stresses accurately, researchers have further considered other complicated theories, such as the higher-order shear deformation theories (HSDT) (Reddy 2004, Thai and Choi 2013 and Han 2014). Mathematically, second-and higher-order plate theories are based on the same assumptions as the CPT and FSDT except that HSDT considers higher order polynomials in the Fourier expansion of the displacement components through the thickness of the plate. In 1980, Levinson proposed a third-order shear deformation theory for an isotropic plate of uniform thickness, and he found there was no need to use the shear correction factor in his theory. Besides that, this theory has been seen to provide a better approximation to the results obtained from FSDT and can give more accurate interlaminar stress distribution. However, higher order stress resultants are difficult to understand physically and require much more computational effort (Reddy, 2004). Moreover, the HSDT does not guarantee the interlaminar continuity (Carrera, 1996).

Although the researches in 2D higher order shear theories (can be treated as a kind of quasi-3D) provide a good predication of some global responses in thin- and mid-thickness plates and an initial understanding of the behaviour of the plates, these theories still provide a rough estimation for the interlaminar stresses through the thickness of a plate and the accuracy of the results decreases as the thickness of plate increases.

To overcome the limitations of various $2 \mathrm{D}$ and /or quasi-3D solutions for plates, the $3 \mathrm{D}$ solutions that take into account the constitutive equations, the kinematic equations, and the stress equilibrium equations in 3D linear elasticity are prevailed. 3D solutions can detail the global and local responses of plates with accurate prediction on the structural behaviour (Han, 2014). Obviously, the accurate prediction for the behaviour of the composite material should be based on 3D rather than 2D approaches (Ye et al., 2004).

One of the 3D plate theories is initiated by (Pagano, 1987). Pagano studied on the plane strain problem of the isotropic and orthotropic laminates under cylindrical bending. As he did not include the normal transverse stress in the equilibrium equation, his solution was still considered as a quasi-3D. However, Pagano did compare his result with that from CPT. He found the CPT solution for stresses and displacements converged to the quasi-3D solution as span to depth ratio increased. It is easy to understand such a phenomenon because the laminates are getting thinner and thinner. What we introduce here the 3D plate theory is called state space approach (SSA) (Wu et al., 2015). It provides accurate three-dimensional solutions that guarantee continuous transverse stress distributions across the thickness of the plates. Also, the boundary conditions and the continuity at the interfaces are satisfied. Besides that, the state space method can give a full range of structural behaviour exactly for various thicknesses from thin to very thick plates (Sheng and Ye, 2003).

The SSA considers all displacement and transverse stress components as the primary state variables simultaneously. The boundary conditions on the top and the bottom surfaces are directly related to them. Initially the approach originated from Vlasov (1957) state variable equation for the solution of the 3D elasticity by using the method of initial functions. Later, it was considered by Bahar (1975) as state space setting for homogeneous and isotropic plates. As one of pioneering researchers in 3D elastic theory, Wu (1987) introduced SSA to a 3D thick plate analysis. Fan and Ye (1990) presented an exact solution based on the state space method for statics and dynamics of orthotropic thick plates with simply supported edges. All fundamental equations of three- 
dimensional elasticity can be exactly satisfied and the nine elastic constants for orthotropic materials can be considered. Besides that the approach extended by Fan and Ye can be applied to the buckling of a thick orthotropic plate. Likewise, Wu and Wardenier (1998) achieved an exact 3D elasticity solution for simply supported thick, orthotropic and rectangular plates subjected to arbitrary loading. In fact, they obtained a sixthorder differential equation governing the transverse displacement for the first time in comparison with the fourthorder differential equation that is used in CPT. Recently; the approach has been extended to the exact analysis of piezoelectric thick laminates in the application of Micro-Electro-Mechanical-System (MEMS).

In this paper, as a novel application of the SSA, the determination of the location of the neutral plane (N.P.) of composite plate will be identified. The N.P. of the plates has a very important role that affects the design of any structure, typical examples including the layout of the reinforced rebar in reinforced concrete slabs and insertion of non-exterminable (non-deformable) sensors in control devices and system. Shifted away of the N.P. from the middle plane could lead unexpected or earlier structural failure for symmetric structural design. Although the importance of the N.P. has been well recognised, the researchers, however, were having different definitions of the N.P. according to their understanding and their experimental work.

In 1773 , Coulomb argued that the summation of the longitudinal tensions across any section should be equal to zero if it was only acted by a system of transverse forces. Todhunter (1887) agreed with Coulomb opinion and he considered that the location of the neutral axis was determined along the axis or middle line of the beam. Riccati (1782) supposed the whole beam was under varying degree of tension, so the neutral plane located in the extreme layer on the concave side. Barlow (1817) assumed that the summation of the moments of the tension fibres above the neutral points of any section was equal to the summation of the moments from the compressed fibres, although he agreed with Coulomb opinion according to his experimental work in (1837). Anderson (1872) said the position of the neutral plane depended on the nature of the material and he defined this plane at or near the centre of the depth of the beam. Adam (1926) suggested that the neutral axis starting in the centre of the beam, moved to the edge of the weaker material as the stress increased. Also, he noticed that if the extreme fibre stresses in the beam could be determined, then the corresponding elongation and shortening which produced by direct stress could be obtained. From the elongation and shortening under a given stress state, the curvature under the loading and the position of neutral axis can be determined.

All of the researchers mentioned above have defined the neutral plane on the basis of linear behaviour of the stresses, strains, or even displacements. Different definitions for the N.P. have not led too much chaos in structural engineering. However, it will demonstrate in this paper that in-plane stresses distribution through the thickness direction in practice can be non-linear. The definition of the N.P. must be specified clearly. The authors in this paper will identify the location of the N.P. when the in-plane stresses are equal to zero following Adam's point of view. In the following investigation of this paper, the space state method, as a powerful 3D analytical approach, is adopted based on the literature review above. The neutral plane of the plate, identified according to the values of the in-plane stresses through the thickness direction, is plotted since the determination of the position of such a plane has been emphasized in a lot of engineering designs and applications.

In addition to that, the effect of the plate thickness on displacements and stresses is described quantitatively. To present the advantages of the $3 \mathrm{D}$ analytical approach for various parameter analyses, two case studies with a finite element analysis as a numerical comparison will be carried out. These analytical results can be further used to assess the accuracy of the finite element analysis. 


\section{SSA Governing Equation}

\subsection{Formulation of the equation}

Consider an elastic homogenous orthotropic rectangular plate of length $a$, width $b$ and uniform thickness $h$ as shown in Figure 1, the elasto-static equilibrium equations of the plate (Ye, 2003) can be written as

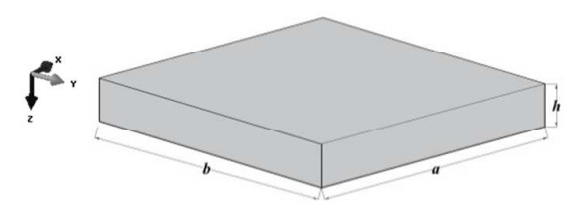

Fig.1. Geometry of a plate.

$$
\begin{aligned}
& \frac{\partial \sigma_{x}}{\partial x}+\frac{\partial \tau_{x y}}{\partial y}+\frac{\partial \tau_{x z}}{\partial z}=0 \\
& \frac{\partial \tau_{x y}}{\partial x}+\frac{\partial \sigma_{y}}{\partial y}+\frac{\partial \tau_{y z}}{\partial z}=0 \\
& \frac{\partial \tau_{x z}}{\partial x}+\frac{\partial \tau_{y z}}{\partial y}+\frac{\partial \sigma_{z}}{\partial z}=0
\end{aligned}
$$

Where $\sigma_{x}, \sigma_{y}$ and $\sigma_{z}$ are normal stresses along $x, y$ and $z$ axes, and $\tau_{x y}, \tau_{y z}$ and $\tau_{x z}$ are shear stresses with respect to $x-y, y-z$ and $x-z$ planes respectively.

Since Hooks law can be applied to elastic materials, the stress-strain relation becomes

$$
\left\{\begin{array}{c}
\sigma_{x} \\
\sigma_{y} \\
\sigma_{z} \\
\tau_{y z} \\
\tau_{x z} \\
\tau_{x y}
\end{array}\right\}=\left[\begin{array}{cccccc}
C_{11} & C_{12} & C_{13} & 0 & 0 & 0 \\
C_{21} & C_{22} & C_{23} & 0 & 0 & 0 \\
C_{31} & C_{32} & C_{33} & 0 & 0 & 0 \\
0 & 0 & 0 & C_{44} & 0 & 0 \\
0 & 0 & 0 & 0 & C_{55} & 0 \\
0 & 0 & 0 & 0 & 0 & C_{66}
\end{array}\right]\left\{\begin{array}{c}
\mathrm{e}_{x} \\
\varepsilon_{y} \\
\varepsilon_{z} \\
\gamma_{y z} \\
\gamma_{x z} \\
\gamma_{x y}
\end{array}\right\}
$$

In equation (2), the strain-displacement relations can be written as

$$
\begin{aligned}
& \varepsilon_{x}=\frac{\partial u}{\partial x}, \varepsilon_{y}=\frac{\partial v}{\partial y}, \varepsilon_{z}=\frac{\partial w}{\partial z}, \\
& \gamma_{y z}=\frac{\partial v}{\partial z}+\frac{\partial w}{\partial y}, \gamma_{x z}=\frac{\partial u}{\partial z}+\frac{\partial w}{\partial x}, \gamma_{x y}=\frac{\partial u}{\partial y}+\frac{\partial v}{\partial x}
\end{aligned}
$$

and

$$
\begin{aligned}
C_{11} & =\frac{E_{1}\left(1-v_{23} v_{32}\right)}{Q} & C_{12} & =\frac{E_{1}\left(v_{21}+v_{31} v_{23}\right)}{Q} \\
C_{22} & =\frac{E_{2}\left(1-v_{13} v_{31}\right)}{Q} & C_{13} & =\frac{E_{1}\left(v_{31}+v_{21} v_{32}\right)}{Q} \\
C_{33} & =\frac{E_{3}\left(1-v_{12} v_{21}\right)}{Q} & C_{23} & =\frac{E_{2}\left(v_{32}+v_{12} v_{31}\right)}{Q}
\end{aligned}
$$


$C_{44}=G_{23}$

$C_{55}=G_{31}$

$C_{66}=G_{12}$

$Q \quad=\quad 1-v_{12} v_{21}-v_{23} v_{32}-v_{31} v_{13}-2 v_{12} v_{23} v_{31}$

$\frac{v_{i j}}{E_{i}}=\frac{v_{j i}}{E_{j}} \quad(i, j=1,2,3)$

Where $E_{1}, E_{2}$ and $E_{3}$ are the Young's moduli of the plate among the material coordinates. The subscripts 1,2 and 3 indicate fibre direction, transverse and perpendicular to the plate respectively. $G_{12}, G_{23}$ and $G_{13}$ are shear moduli with respect to 1-2, 2-3 and 1-3 planes respectively. $v_{12}, v_{23}$ and $v_{13}$ are the Poisson's ratios correspondingly.

From equation (2), all stress components can be expressed explicitly:

$\sigma_{x}=C_{11} \frac{\partial u}{\partial x}+C_{12} \frac{\partial v}{\partial y}+C_{13} \frac{\partial w}{\partial z}$

$\sigma_{y}=C_{12} \frac{\partial u}{\partial x}+C_{22} \frac{\partial v}{\partial y}+C_{23} \frac{\partial w}{\partial z}$

$\sigma_{z}=C_{13} \frac{\partial u}{\partial x}+C_{23} \frac{\partial v}{\partial y}+C_{33} \frac{\partial w}{\partial z}$

$\tau_{y z}=C_{44}\left(\frac{\partial v}{\partial z}+\frac{\partial w}{\partial y}\right)$

$\tau_{x z}=C_{55}\left(\frac{\partial u}{\partial z}+\frac{\partial w}{\partial x}\right)$

$\tau_{x y}=C_{66}\left(\frac{\partial u}{\partial y}+\frac{\partial v}{\partial x}\right)$

Three displacements in $x-y-z$ directions, labelled with $u, v$ and $w$, respectively, and the transverse stresses $\sigma_{z}, \tau_{x z}$ and $\tau_{y z}$, are solved with respect to the $z$ coordinate directly from the equations (1), (3) and (5),

$\frac{\partial u}{\partial z}=\frac{\tau_{x z}}{C_{55}}-\frac{\partial w}{\partial x}$

$\frac{\partial v}{\partial z}=\frac{\tau_{y z}}{C_{44}}-\frac{\partial w}{\partial y}$

$\frac{\partial w}{\partial z}=\frac{\sigma_{z}}{C_{33}}-\frac{C_{13}}{C_{33}} \frac{\partial u}{\partial x}-\frac{C_{23}}{C_{33}} \frac{\partial v}{\partial y}$

$\frac{\partial \sigma_{z}}{\partial z}=-\frac{\partial \tau_{x z}}{\partial x}-\frac{\partial \tau_{y z}}{\partial y}$

$\frac{\partial \tau_{x z}}{\partial z}=-\frac{\partial \sigma_{x}}{\partial x}-\frac{\partial \tau_{x y}}{\partial y}=\left[-\left(C_{11}-\frac{C_{13}^{2}}{C_{33}}\right) \frac{\partial^{2}}{\partial x^{2}}-C_{66} \frac{\partial^{2}}{\partial y^{2}}\right] u-\left[\left(C_{12}-\frac{C_{13} C_{23}}{C_{33}}\right)+C_{66}\right] \frac{\partial^{2} v}{\partial x \partial y}-\frac{C_{13}}{C_{33}} \frac{\partial \sigma_{z}}{\partial x}$

$\frac{\partial \tau_{y z}}{\partial z}=-\frac{\partial \tau_{x y}}{\partial x}-\frac{\partial \sigma_{y}}{\partial y}=-\left[\left(C_{12}-\frac{C_{13} C_{23}}{C_{33}}\right)+C_{66}\right] \frac{\partial^{2} u}{\partial x \partial y}+\left[-C_{66} \frac{\partial^{2}}{\partial x^{2}}-\left(C_{22}-\frac{C_{23}{ }^{2}}{C_{33}}\right) \frac{\partial^{2}}{\partial y^{2}}\right] v-\frac{C_{23}}{C_{33}} \frac{\partial \sigma_{z}}{\partial y}$ 
Denoting
$C_{1}=-\frac{C_{12}}{C_{33}}$
$C_{2}=C_{11}-\frac{C_{12}{ }^{2}}{C_{33}}$
$C_{3}=C_{12}-\frac{C_{13} C_{23}}{C_{33}}$
$C_{4}=C_{22}-\frac{C_{23}{ }^{2}}{C_{33}}$
$C_{5}=-\frac{C_{23}}{C_{33}}$
$C_{6}=C_{66}$
$C_{7} \quad=\frac{1}{C_{33}}$
$C_{8}=\frac{1}{C_{55}}$
$C_{9} \quad=\frac{1}{C_{44}}$

and rearranging equation (6) leads to a matrix form as:

$$
\frac{\partial}{\partial z}\{\mathrm{~F}\}=[\mathrm{G}]\{\mathrm{F}\}
$$

Herein, $\{\mathrm{F}\}=\left[u v \sigma_{z} \tau_{x z} \tau_{y z} w\right]^{T}$ is called the state vector of the plate and [G] is named as the system state matrix

$$
[\mathrm{G}]=\left[\begin{array}{cccccc}
0 & 0 & 0 & C_{8} & 0 & -\frac{\partial}{\partial x} \\
0 & 0 & 0 & 0 & C_{9} & -\frac{\partial}{\partial y} \\
0 & 0 & 0 & -\frac{\partial}{\partial x} & -\frac{\partial}{\partial y} & 0 \\
-C_{2} \frac{\partial^{2}}{\partial x^{2}}-C_{6} \frac{\partial^{2}}{\partial y^{2}} & -\left(C_{3}+C_{6}\right) \frac{\partial^{2}}{\partial x \partial y} & C_{1} \frac{\partial}{\partial x} & 0 & 0 & 0 \\
-\left(C_{3}+C_{6}\right) \frac{\partial^{2}}{\partial x \partial y} & -C_{6} \frac{\partial^{2}}{\partial x^{2}}-C_{4} \frac{\partial^{2}}{\partial y^{2}} & C_{5} \frac{\partial}{\partial y} & 0 & 0 & 0 \\
C_{1} \frac{\partial}{\partial x} & C_{5} \frac{\partial}{\partial y} & C_{7} & 0 & 0 & 0
\end{array}\right]
$$

Once the state vector containing the three displacements and the transverse stresses $\left[\sigma_{z}, \tau_{x z}, \tau_{y z}\right]$ has been found, the three in-plane stresses in the $x-y$ plane can be calculated from equation (5) as following:

$$
\left\{\begin{array}{c}
\sigma_{x} \\
\sigma_{y} \\
\tau_{x y}
\end{array}\right\}=\left[\begin{array}{cccccc}
C_{2} \frac{\partial}{\partial x} & C_{3} \frac{\partial}{\partial y} & -C_{1} & 0 & 0 & 0 \\
C_{3} \frac{\partial}{\partial x} & C_{4} \frac{\partial}{\partial y} & -C_{5} & 0 & 0 & 0 \\
C_{6} \frac{\partial}{\partial y} & C_{6} \frac{\partial}{\partial x} & 0 & 0 & 0 & 0
\end{array}\right]\left\{\begin{array}{c}
u \\
v \\
\sigma_{z} \\
\tau_{x z} \\
\tau_{y z} \\
w
\end{array}\right\}
$$

To consider a rectangular plate with the boundary conditions for the four sides of the simply supported plate (Figure 1), the following boundary condition should be satisfied:

$$
\begin{array}{ll}
\sigma_{x}=v=w=0 & (\text { at } x=0, a) \\
\sigma_{y}=u=w=0 & (\text { at } y=0, b)
\end{array}
$$


In order to satisfy the boundary conditions specified in equation (11), the following six state variables of the state vector can be expressed by:

$$
\begin{aligned}
u(x, y, z) & =\sum_{m=1} \sum_{n=1} U_{m n}(z) \cos (m \pi x / a) \sin (n \pi y / b) \\
v(x, y, z) & =\sum_{m=1} \sum_{n=1} V_{m n}(z) \sin (m \pi x / a) \cos (n \pi y / b) \\
w(x, y, z) & =\sum_{m=1} \sum_{n=1} W_{m n}(z) \sin (m \pi x / a) \sin (n \pi y / b) \\
\tau_{x z}(x, y, z) & =\sum_{m=1} \sum_{n=1} X_{m n}(z) \cos (m \pi x / a) \sin (n \pi y / b) \\
\tau_{y z}(x, y, z)= & \sum_{m=1} \sum_{n=1} Y_{m n}(z) \sin (m \pi x / a) \cos (n \pi y / b) \\
\sigma_{z}(x, y, z)= & \sum_{m=1} \sum_{n=1} Z_{m n}(z) \sin (m \pi x / a) \sin (n \pi y / b)
\end{aligned}
$$

Let $\zeta=m \pi x / a$ and $\eta=n \pi y / b$ where $m$ and $n$ are the number of looping of the analytical solution in the $x$ and $y$ directions respectively and substituting equation (12) into equation (8) yields for each combination of $m$ and $n$

$$
\frac{\partial}{\partial z}\left\{\mathrm{~F}_{m n}(z)\right\}=\left[\mathrm{G}_{m n}\right]\left\{\mathrm{F}_{m n}(z)\right\}
$$

Herein, $\left\{\mathrm{F}_{m n}(z)\right\}=\left[U_{m n}(z) V_{m n}(z) Z_{m n}(z) X_{m n}(z) Y_{m n}(z) W_{m n}(z)\right]^{T}$ is the state vector of the plate with the number of looping $m-n^{\text {th }}$ and the system matrix is

$$
\left[\mathrm{G}_{m n}\right]=\left[\begin{array}{cccccc}
0 & 0 & 0 & C_{8} & 0 & -\zeta \\
0 & 0 & 0 & 0 & C_{9} & -\eta \\
0 & 0 & 0 & \zeta & \eta & 0 \\
C_{2} \zeta^{2}+C_{6} \eta^{2} & \left(C_{3}+C_{6}\right) \zeta \eta & C_{1} \zeta & 0 & 0 & 0 \\
\left(C_{3}+C_{6}\right) \zeta \eta & C_{6} \zeta^{2}+C_{4} \eta^{2} & C_{5} \eta & 0 & 0 & 0 \\
-C_{1} \zeta & -C_{5} \eta & C_{7} & 0 & 0 & 0
\end{array}\right]
$$

\subsection{Solution of the equation}

By solving the differential equation (13) based on classical solution method of a linear differential equation (Stroud, 2013), the solution can be found as:

$$
\left\{\mathrm{F}_{m n}(z)\right\}=\left[\mathrm{D}_{m n}(z)\right]\left\{\mathrm{F}_{m n}(0)\right\}
$$

where $\left[\mathrm{D}_{m n}(z)\right]=\exp \left\{\left[\mathrm{G}_{m n}\right] z\right\}$, and when $z=h$,

$$
\left\{\mathrm{F}_{m n}(h)\right\}=\left[\mathrm{D}_{m n}(h)\right]\left\{\mathrm{F}_{m n}(0)\right\}
$$


$\left\{\mathrm{F}_{m n}(0)\right\}$ and $\left\{\mathrm{F}_{m n}(h)\right\}$ are the values of the state variables on top $(z=0)$ and bottom $(z=h)$ surfaces. They can be determined uniquely on the basis of the load conditions on the top and bottom surfaces of the plate. For example, if the plate is subjected to an arbitrarily distributed external transverse pressure $q(x, y)$ on the top surface only, the state vectors on the top and bottom surfaces of the plate can be expanded into Fourier series as shown in equations (17) and (18), respectively:

$$
\left\{\mathrm{F}_{m n}(0)\right\}=\left\{\begin{array}{c}
U_{m n}(0) \\
V_{m n}(0) \\
a b \int_{0}^{a} \int_{0}^{b} q(x, y) \sin (m \pi x / a) \sin (n \pi y / b) d x d y \\
0 \\
0 \\
W_{m n}(0)
\end{array}\right\}
$$

and

$$
\left\{\mathrm{F}_{m n}(h)\right\}^{T}=\left[\begin{array}{lllllll}
U_{m n}(h) & V_{m n}(h) & 0 & 0 & 0 & W_{m n}(h)
\end{array}\right]
$$

Further formulation simplification can be used if $q(x, y)=q$ is a constant, and

$$
\frac{4}{a b} \int_{0}^{a} \int_{0}^{b} q(x, y) \sin (m \pi x / a) \sin (n \pi y / b) d x d y= \begin{cases}0 & (m, n=2,4,6, \ldots \ldots) \\ \frac{-16 q}{m n \pi^{2}} & (m, n=1,3,5, \ldots \ldots)\end{cases}
$$

Substituting equations (17) and (18) into (16), it is easy to get all displacement components on the top and the bottom surfaces of the plate, that is, $U_{m n}(0), V_{m n}(0), W_{m n}(0)$ and $U_{m n}(h), V_{m n}(h), W_{m n}(h)$.

After finding all the displacements and the transverse stresses, the in-plane stresses can be found by using the following equation:

$$
\left\{\begin{array}{c}
\sigma_{x} \\
\sigma_{y}
\end{array}\right\}=\left[\begin{array}{cccccc}
-C_{2} \zeta & -C_{3} \eta & -C_{1} & 0 & 0 & 0 \\
-C_{3} \zeta & -C_{4} \eta & -C_{5} & 0 & 0 & 0 \\
C_{6} \eta & C_{6} \zeta & 0 & 0 & 0 & 0
\end{array}\right]\left\{\begin{array}{c}
u \\
v \\
\sigma_{z} \\
\tau_{x z} \\
\tau_{y z} \\
w
\end{array}\right\}
$$

\section{Analysis and Results}

Two case studies are analysed by using the SSA and FEM for the determination of structural behaviour of simply supported orthotropic composite plates under two types of loading. For the first case, the loading is an anti-symmetrical half-single sine distributed out-of-plane and in the second case, the load is uniformly distributed. The numerical results from a finite element model developed in ABAQUS, for comparison, are provided with those obtained by using SSA with different parametric studies.

\subsection{Case 1}

In this case, the geometry of the composite plate is $a=b$ and $h / a=0.2,0.3$ and 0.5 . Where $a$ is the length of the plate along $x$-axis, $b$ is the width of the plate along $y$-axis and $h$ is the thickness of the plate along $z$-axis as shown in Figure 1. 
The set of elastic material parameters used are given as per (Wu, 1987):

$E_{1}=10 E_{2}=10 E_{3}, G_{12}=G_{13}=0.6 E_{3}, G_{23}=0.5 E_{3}, v_{12}=v_{13}=v_{23}=0.25$.

The plate is simply-supported for all sides and the loading is an anti-symmetrical half single sine distributed outof- plane load $\frac{q}{2} \sin \left(\frac{\pi x}{a}\right) \sin \left(\frac{\pi y}{b}\right)$. Hence, $Z_{m n}(z)$ at the top $(z=0)$ and the bottom $(z=h)$ surfaces of the plate are equal to $-q / 2$ and $q / 2$, respectively.

In the next section, the numerical results are given by using ABAQUS and the results are compared with those from the SSA analytical solution in order to illustrate the precision of these methods.

\subsection{Parametric Studies}

For comparison purpose and illustratation of the advantages of the SSA, numerical precision in FEM should be as accurate as possible. In order to determine an accurate FEM model, different element types and mesh sizes are considered firstly. It can demonstrate the power of the SSA without any ambiguity and provides a clear quantitative profile of 'to what extent, the stress analysis results from an FEM model can be treated as acceptable and what kind of element type and element size are more appropriate if a precision of FEM simulation is acceptable'. Then, the effect of thickness to width ratios of the plate on the analytical results can be presented and discussed systematically.

\section{- Element type}

According to Table I, four different solid elements have been studied; Reduced integrated 3D 8-node linear brick element (C3D8R), Fully integrated 3D 8-node linear brick element (C3D8), Reduced integrated 3D 20-node linear brick element (C3D20R) and Fully integrated 3D 20-node linear brick element (C3D20) (ABAQUS, 2013). The results have been compared with the SSA for in- and out- of-plane displacements and stresses. The solid element was used in this paper instead of the shell element because the solid element can show all the displacements and the stresses through the thickness of the plate.

In Table I, the negative relative errors mean the FEM gives larger value than the SSA and this leads to overestimated results. The elements with 8-node (C3D8R and C3D8) overestimate the displacement results $(u, v$ and $w)$ at the same time they give less value for the stresses $\left(\sigma_{x}, \sigma_{y}\right.$ and $\left.\sigma_{z}\right)$. On the other hand, the elements with 20-node (C3D20R and C3D20) overestimate the stresses comparing to the SSA. From this quantitative comparison, the best FE element type that gives more consistent results with the SSA with a minimum relative error is C3D20. On the basis of this observation, the numerical model with this element type would be adopted accordingly in the following numerical calculations to compare with the SSA results. 
Table I. Relative errors for solid elements at $z=h$ for $h / a=0.2$.

\begin{tabular}{|c|c|c|c|c|c|c|c|c|c|c|}
\hline & & \multirow[b]{2}{*}{ SSA } & \multicolumn{2}{|c|}{ C3D8R } & \multicolumn{2}{|c|}{ C3D8 } & \multicolumn{2}{|c|}{ C3D20R } & \multicolumn{2}{|c|}{ C3D20 } \\
\hline & & & Values & $\begin{array}{c}\text { Relative } \\
\text { Error (\%) }\end{array}$ & Values & $\begin{array}{c}\text { Relative } \\
\text { Error (\%) }\end{array}$ & Values & $\begin{array}{c}\text { Relative } \\
\text { Error (\%) }\end{array}$ & Values & $\begin{array}{c}\text { Relative } \\
\text { Error (\%) }\end{array}$ \\
\hline \multicolumn{2}{|c|}{$u . E_{3} / q h$ at $x=0$ and $y=b / 2$} & -1.74625 & -1.87304 & -7.3 & -1.86204 & -6.6 & -1.68498 & 3.5 & -1.79068 & -2.5 \\
\hline \multicolumn{2}{|c|}{$v \cdot E_{3} / q h$ at $x=a / 2$ and $y=0$} & -2.42681 & -2.71048 & -11.7 & -2.55635 & -5.3 & -2.07370 & 14.6 & -2.27685 & 6.2 \\
\hline$w \cdot E_{3} / q h$ & \multirow{6}{*}{ 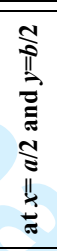 } & 8.82332 & 9.31376 & -5.6 & 9.30444 & -5.5 & 9.29750 & -5.4 & 9.29749 & -5.4 \\
\hline$\sigma_{x} / q$ & & 11.58183 & 11.11267 & 4.1 & 11.43132 & 1.3 & 12.15463 & -4.9 & 12.17926 & -5.2 \\
\hline$\sigma_{\mathrm{y}} / q$ & & 1.93935 & 1.86762 & 3.7 & 1.89783 & 2.1 & 2.00208 & -3.2 & 2.00374 & -3.3 \\
\hline$\sigma_{z} / q$ & & $\begin{array}{l}0.50000 \\
\end{array}$ & 0.49385 & 1.2 & $\begin{array}{l}0.48491 \\
\end{array}$ & 3.0 & $\begin{array}{l}0.50197 \\
\end{array}$ & -0.4 & 0.50299 & -0.6 \\
\hline$\tau_{x z} / q$ & & 0.00000 & 0.00000 & 0.0 & 0.00000 & 0.0 & 0.00000 & 0.0 & 0.00000 & 0.0 \\
\hline $\bar{\tau} \tau_{y z} / q$ & & 0.00000 & 0.00000 & 0.0 & 0.00000 & 0.0 & 0.00000 & 0.0 & 0.00000 & 0.0 \\
\hline \multicolumn{2}{|c|}{$\tau_{x y} / q$ at $x=0$ and $y=0$} & -1.57320 & -1.11226 & 29.3 & -1.22090 & 22.4 & -1.21522 & 22.8 & $\begin{array}{l}-1.21764 \\
\end{array}$ & 22.6 \\
\hline
\end{tabular}

- Mesh size

Mesh sensitivity test was taken to check which mesh size from three different sizes would be more appropriate for particular cases. The three mesh sizes are $0.25,0.125$ and 0.0625 respectively. Due to anti-symmetric half single sine distributed out -of- plane loading, the numerical results for the out -of- plane stress $\sigma_{z}$ should be equal to $-q / 2$ or $q / 2$ on the top and bottom surfaces of the plate. These values can be used to confirm the accuracy of the numerical results from FEM. As shown in Table II and Figure 2, for the out -of- plane stress $\sigma_{z}$ results, when the mesh sizes of the elements decrease, its relative error with respect to the exact solution will be smaller and the results will be more accurate. For this reason, the finest mesh (Mesh 3) will be used in the current FEM analysis.

Table II. Relative errors for different mesh sizes at $z=h$ for $h / a=0.2$.

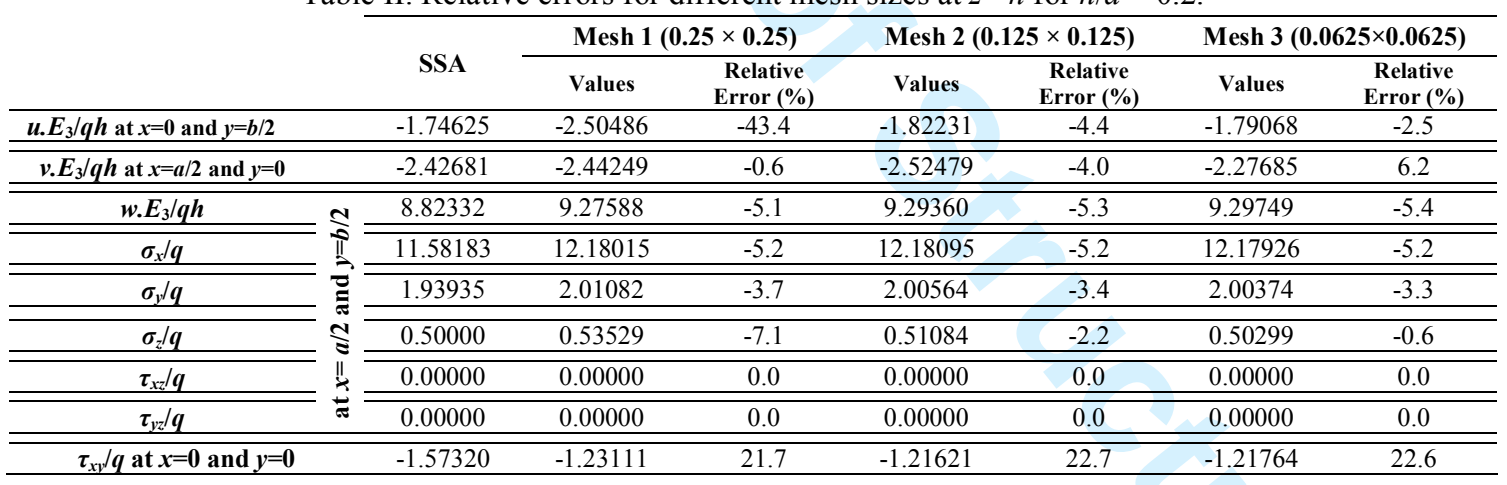

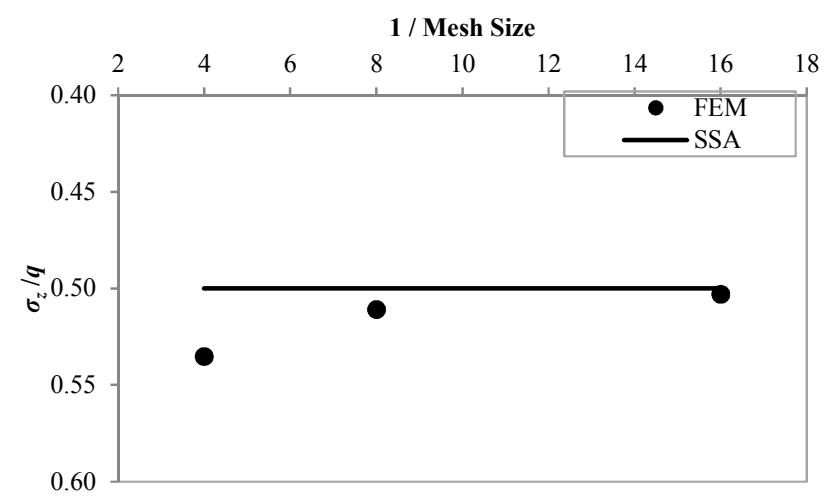

Fig.2. Different mesh sizes results for $\sigma_{z} / q$ at $z=h$ for $h / a=0.2$. 
- Thickness to width ratio

Since the loading in the structure of Case 1 is anti-symmetric, one of the advantages by using the SSA is that the capability of this approach to get an exact solution is demonstrated. Because all boundary conditions of the six edge surfaces (four sides, together with top and bottom surfaces), each surface has been described by three mixture stresses and/or displacements, are satisfied exactly. All equilibrium equations, kinematic equations and Hooke's law in 3D elasticity are fully covered and considered without any assumption and omission under the frame of the SSA. It is hence safely to say that solution sought under this case is exact and the effect of the thickness to width ratios $(h / a)$ on the plate structural behaviour can be determined quantitatively. Figure 3 shows the effect of $h / a$ on the in-plane stress $\sigma_{x}$. The nonlinear behaviour of the stress across the thickness can be observed clearly as $h / a$ increases. Since the SSA describes the exact response of the plate, this figure shows that the linear stress distribution assumption through the thickness direction in CPT assumption is inappropriate. From the same figure, it is seen that for all $h / a$ ratios, FEM gives non-conservative larger values for the stress through the thickness in comparison with those from the SSA.

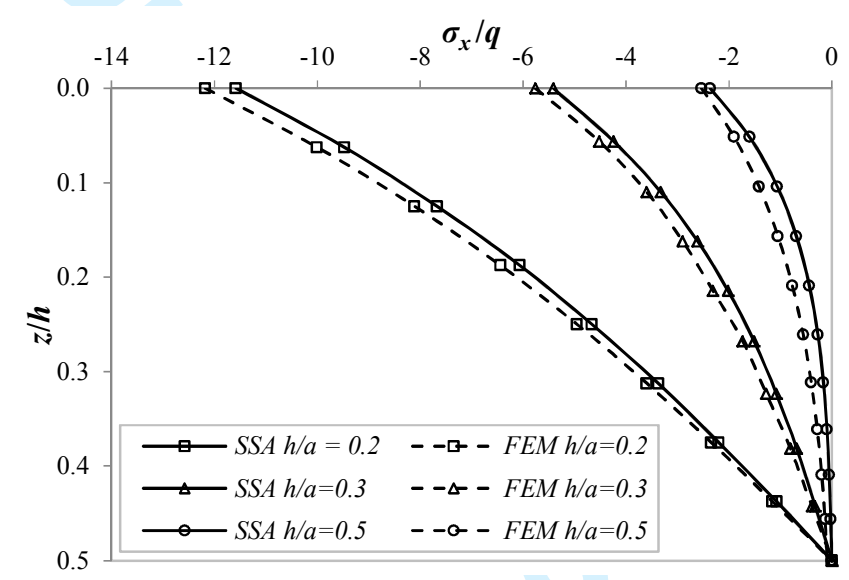

Fig.3. The effect of different $h / a$ on the in-plane stress $\left(\sigma_{x} / q\right)$ through the thickness.

\subsection{Case 2}

In this case, the geometry, material properties and the boundary conditions of the plate are the same as Case 1 . The only difference with Case 1 is that the loading on top surface of the plate is uniformly distributed $q(x, y)=q$ and the loading on the bottom surface of the plate is nill.

For the same reason with the selection of the element type, as stated in Case 1, the precision comparison in this case study would be the element type C3D20 with the mesh size $(0.0625 \times 0.6025)$. Details for the precision of the FE results comparing to the SSA as an exact solution can be referred to Kamis (2012) in which different finite element types with different mesh sizes have been discussed. Table III shows the SSA and FEM results for the displacements and stresses of the composite plate. The results show that the FE results are overestimated the values of the displacements and the in-plane normal stresses. On the other hand, it gives more conservative values for all of the shear stresses.

To give the variation of the results between the SSA and the FEM, Figure 4 shows the distribution of $w$ through the thickness. Obviously, the FE gives larger values comparing to the exact solution. In contrast, the FE results present more conservative solutions for the transverse shear stress $\tau_{x z}$ and the peak value is not at the same 
position along the thickness as the SSA prediction as shown in Figure 5. In addition, the FE results for $\tau_{x z}$ at the top and the bottom of the plate are equal to -0.052 and 0.056 respectively. Although these values are small, the FE results are not much precise as the shear stress $\tau_{x z}$ should be zeros at the top and the bottom of the plate.

Table III. In- and out- of- plane displacements and stresses of Case 2 for $h / a=0.2$.

\begin{tabular}{|c|c|c|c|c|c|c|c|c|c|c|}
\hline & & $u . E_{3} / q h$ & $v \cdot E_{3} / q h$ & $w \cdot E_{3} / q h$ & $\sigma_{x} / \boldsymbol{q}$ & $\sigma_{y} / q$ & $\tau_{x y} / \boldsymbol{g}$ & \multirow{6}{*}{$\begin{array}{c}=1 \mathrm{~N} \\
=1 \mathrm{~N} \\
\mathrm{~N}\end{array}$} & $\tau_{x z} / \boldsymbol{q}$ & $\tau_{y z} / \boldsymbol{q}$ \\
\hline & & $\left(0, \frac{b}{2}\right)$ & $\left(\frac{a}{2}, 0\right)$ & $\left(\frac{a}{2}, \frac{b}{2}\right)$ & $\left(\frac{a}{2}, \frac{b}{2}\right)$ & $\left(\frac{a}{2}, \frac{b}{2}\right)$ & $(0,0)$ & & $\left(0, \frac{b}{2}\right)$ & $\left(\frac{a}{2}, 0\right)$ \\
\hline \multirow{2}{*}{ SSA } & Top & 2.8917 & 4.2289 & 13.7081 & -17.0107 & -2.4682 & 3.5693 & & \multirow{2}{*}{3.9013} & \multirow{2}{*}{1.7073} \\
\hline & Bottom & -2.8001 & -4.4203 & 13.2274 & 16.9643 & 2.4175 & -3.0743 & & & \\
\hline \multirow{2}{*}{$\begin{array}{c}\text { FEM } \\
(3 \mathrm{D} 20)\end{array}$} & Top & 3.2463 & 4.2346 & 14.4692 & -18.0694 & -2.6772 & 2.0927 & & \multirow{2}{*}{3.5616} & \multirow{2}{*}{1.5101} \\
\hline & Bottom & -2.9710 & -5.5039 & 13.9651 & 18.0115 & 2.67446 & -2.0927 & & & \\
\hline
\end{tabular}

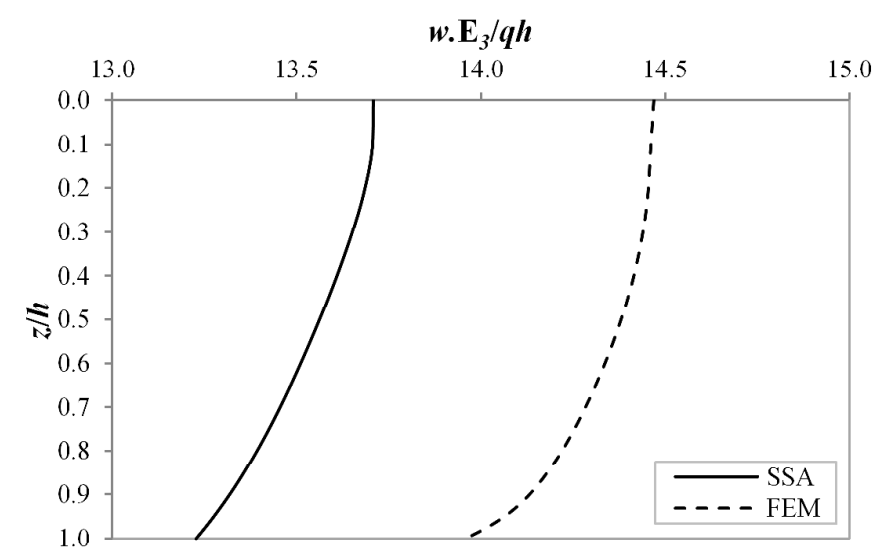

Fig.4. Out -of- plane displacement (w) distribution through the thickness for the plate with $h / a=0.2$.

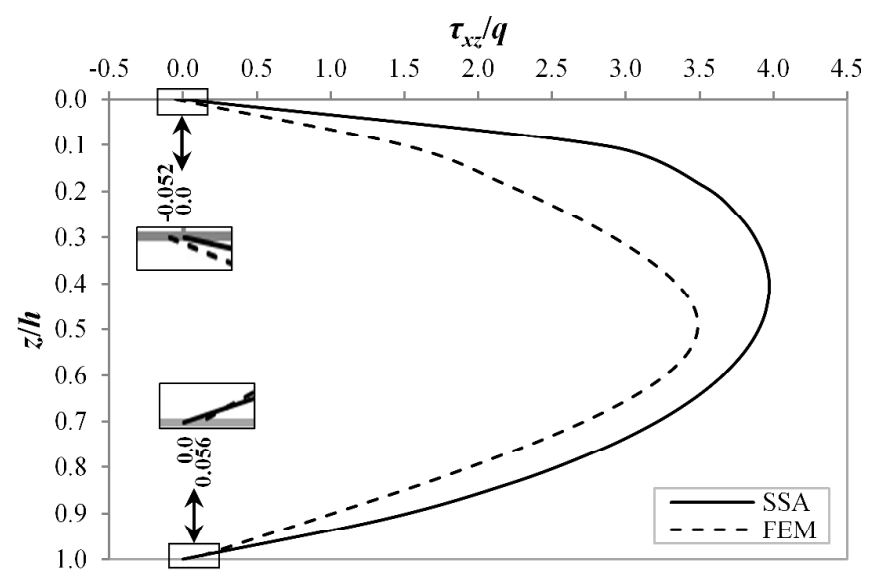

Fig.5. Transverse shear stress $\left(\tau_{x z} / q\right)$ distribution through the thickness for the plate with $h / a=0.2$.

By using the SSA to calculate the precise values of the stresses, the accurate distribution of the in-plane stress $\sigma_{x}$ through the thickness of the plate is presented in Figures $6 \& 7$ and the nonlinear behaviour for it is clearly noticed. Accordingly, a neutral axis (N.A.) can be identified when the in-plane stresses $\left(\sigma_{\mathrm{r}}\right.$ and $\left.\sigma_{y}\right)$ are equal to zero -as mentioned before in the introduction- and it can be noticed in Figure 6 that the location of the neutral axis will be shifted away (downward in a specific case as Figure 6) from the middle plane of the plate depending 
on the direction of the load. For different locations along $x$ and $y$-axes, the precise in-plane stresses through the thickness are drawn in Figures $7 \& 8$ and the N.A. for each location is identified. Naturally, the neutral plane (N.P.) can be extended from the N.A. through the thickness direction of the plate in $x-y$ plane as shown in Figure 9.

The unsymmetrical shape of the N.P. in $x-y$ plane caused by the different values of the material properties in $x$ and $y$ directions as the material that used in this case is orthotropic with different Young modulus $E$ in $x$ and $y$ directions. In addition, the different values of the in-plane stresses $\sigma_{x}$ and $\sigma_{y}$ will effect on the location of the N.P. Through the thickness direction, the location of the N.P. is ranged from 0.46 to 0.51 when $\sigma_{x}$ is equal to zero and from 0.48 to 0.55 when $\sigma_{y}$ is equal to zero as shown in Figure 9. All of these results are shifted downward or upward from the middle plane of the plate.

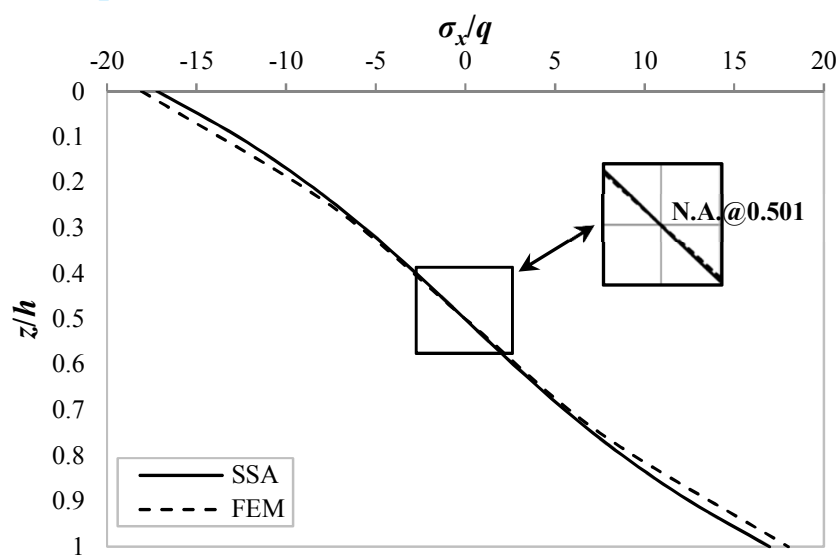

Fig.6. In-plane stress $\left(\sigma_{x} / q\right)$ distribution through the thickness for $x / a, y / b=0.5$ and $h / a=0.2$.

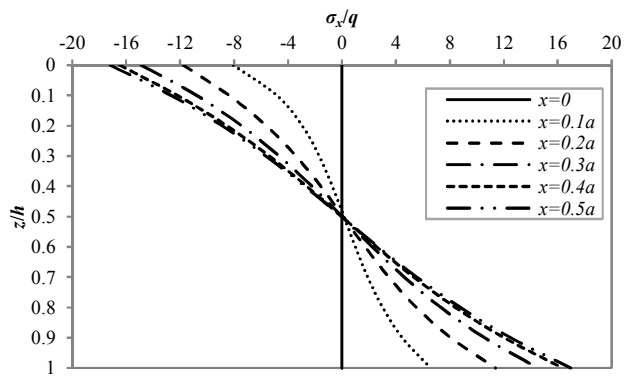

(a) $y=0.5 b$

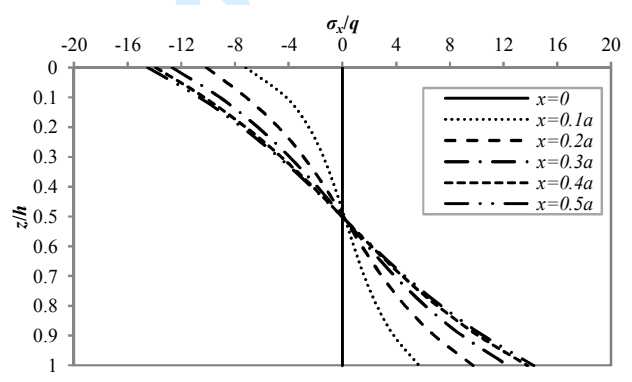

(b) $y=0.3 b$

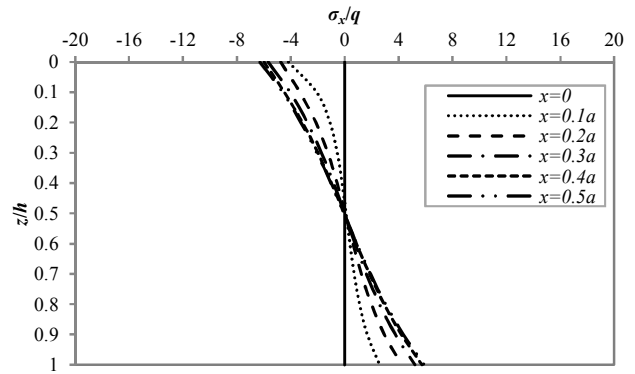

(c) $y=0.1 b$

Fig.7. In-plane stress $\left(\sigma_{x} / q\right)$ distributions through the thickness $(h / a=0.2)$ for different locations along $x$ and $y$. 

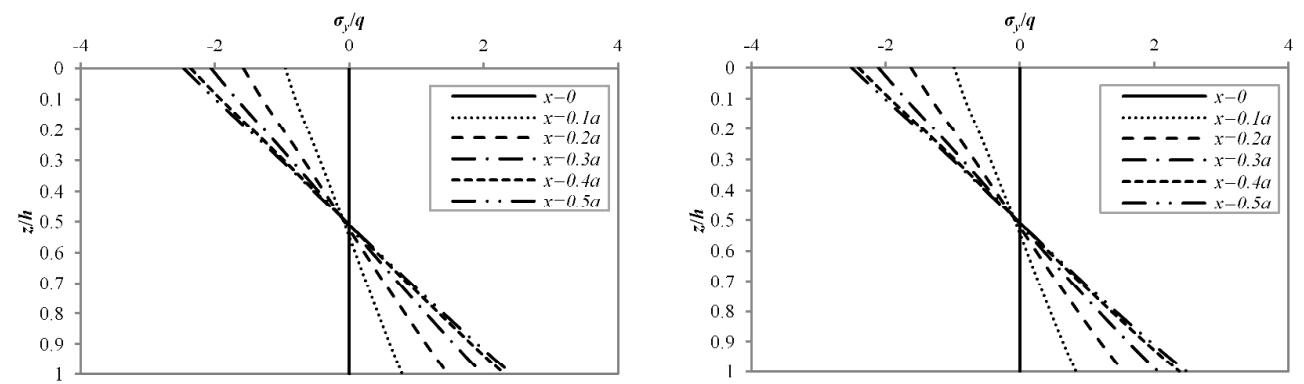

(a) $y=0.5 b$

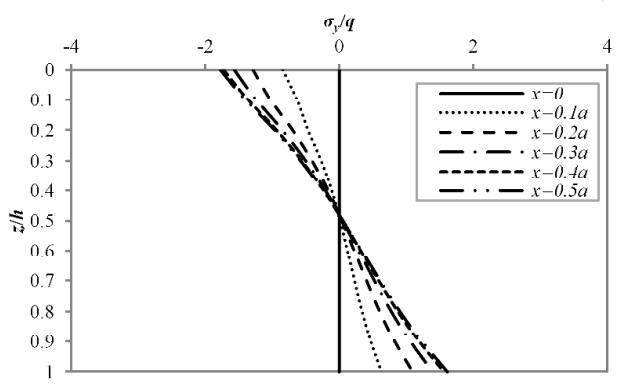

(c) $y=01 \mathrm{~h}$

Fig.8. In-plane stress $\left(\sigma_{y} / q\right)$ distributions through the thickness $(h / a=0.2)$ for different locations along $x$ and $y$.

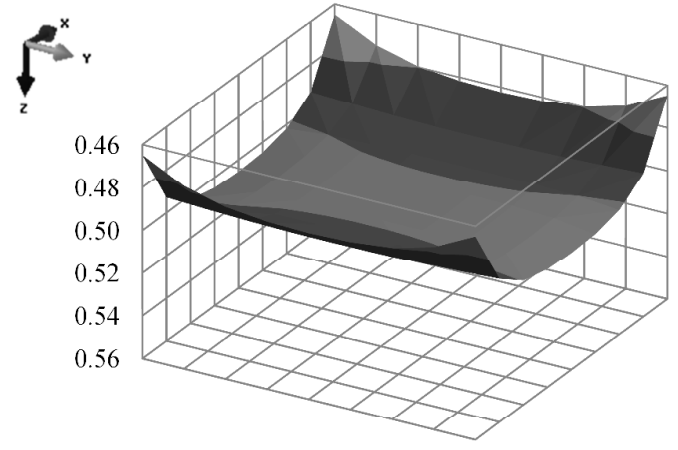

(a)

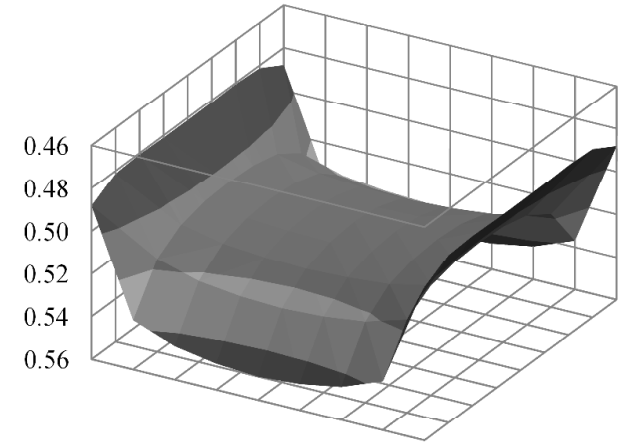

(b)

Fig.9. The neutral plane of the plate $(h / a=0.2)$ through the thickness direction in cases of (a) $\sigma_{x}=$ zero and (b) $\sigma_{y}=0$.

\section{Conclusions}

An analytical investigation has been carried out for a simply supported rectangular plate with two different loading conditions by using 3D SSA. The SSA, as a powerful three-dimensional approach, satisfies all the boundary conditions and the continuity at the interfaces. It provides accurate $3 \mathrm{D}$ solutions that guarantee continuous transverse stress distributions across the thickness of the plates. Besides that, the state space method can give precise results for all in- and out- of- plane stresses and displacements for various thicknesses from thin to very thick plates. By applying the SSA, it is found that the behaviour of the stresses through the thickness becomes nonlinear especially for plates with higher thickness to width ratio $(h / a)$. Also, the accurate location of the neutral plane through the thickness of the plate can be identified: the neutral plane is shifted away from the middle plane according to the loading condition.

Furthermore, the finite element models developed in ABAQUS overestimate some of the results such as almost all of displacement components and in-plane normal stresses while shear stresses in FEM are more conservative 
in comparison with those of the SSA. More caution is required when using numerical results from the FEM are applied for real structural design and behaviour evaluation.

\section{Acknowledgement}

The authors gratefully acknowledge the contribution of University of Petra, Jordan, to fund this research.

\section{References}

ABAQUS (2013), User's Manual, Version 6.13, Dassault Systémes Simulia Corp., Providence, Rhode.

Adam, H. (1926). The Neutral Axis in Beams. The structural Engineer, 4(9), pp.274-281.

Anderson, J. (1872), The Strength of Materials and Structures, D. Appleton and Co., New York, $1^{\text {st }}$ edition.

Bahar, L.Y. (1975). A State Space Approach to Elasticity. Journal of the Franklin Institute, pp.33-41.

Barlow, P. (1817), An Essay on The Strength and Stress of Timber, J. Taylor, London, $3^{\text {rd }}$ edition.

Carrera, E. (1996). Elements Including Zig-Zag and Interlaminar Stress Continuity. International Journal for Numerical Methods in Engineering. 39, pp.1797-1820.

Coulomb, C. A. (1773). Essai Sur Une Application Des Regles De Maximis Et Minimis A Quelques Problemes De Statique Relatifs A L'architecture (Essay on Maximums and Minimums of Rules to Some Static Problems Relating to Architecture). Academie Royale Des Sciences, 7.

Fan, J. and Ye, J. (1990). An Exact Solution for the Statics and Dynamics of Laminated Thick Plates with Orthotropic Layers. International Journal of Solids and Structures, 26(7), pp.655-662.

Ghugal Y. M. and Shimpi R. P. (2002). A Review of Refined Shear Deformation Theories of Isotropic and Anisotropic Laminated Plates. Journal of Reinforced Plastics and Composites, 21(9), p.775.

Han, C. (2014). 3D State Space Analysis and Free-Edge Effect of Piezoelectric Laminated Thick Plates. PhD dissertation, School of MACE, the University of Manchester.

Kamis, E. (2012). Three Dimensional Analysis of Fibre Reinforced Polymer Laminated Composites. PhD dissertation, School of MACE, the University of Manchester.

Kirchhoff, G. (1850). Uber das Gleichgewicht und die Bewegung einer elastischen Scheibe. Journal für die reine und angewandte Mathematik, 40, pp.51-88.

Kreja, I. (2011). A Literature Review on Computational Models for Laminated Composite and Sandwich Panels. Central European Journal of Engineering, 1(1), pp.59-80.

Levinson, M. (1980). An Accurate, Simple Theory of the Statics and Dynamics of Elastic Plates. Mechanics Research Communications, 7(6), pp.343-350.

Pagano, N.J. (1987). Exact Solutions for Composite Laminates in Cylindrical Bending. Composite Materials, 3 , pp. 398-411.

Rashed, Y. F. (2000). Boundary Element Formulations for Thick Plates, WIT press.

Reddy, J. N. (2004). Mechanics of Laminated Composite Plates and Shells: Theory and Analysis, CRC press.

Reissner, E. (1945). The Effect of Transverse Shear Deformation on the Bending of Elastic Plates. Journal of Applied Mechanics, 12, 69-77.

Riccati, G. (1782). Delle vibrazioni sonore dei cilindri, Memoria di Matematica e di Fisica della Societa Italiana, 1.

Rolfes, R., Rohwer, K. and Ballerstaedt, M. (1998). Efficient Linear Transverse Normal Stress Analysis of Layered Composite Plates. Computers \& Structures, 68(6), pp.643-652.

Sheng, H.Y. and Ye, J.Q. (2003). A Three-Dimensional State Space Finite Element Solution for Laminated Composite Cylindrical Shells. Computer Methods in Applied Mechanics and Engineering, 192(22-24), pp.24412459 .

Stroud, K.A. (2013). Engineering Mathematics. $7^{\text {th }}$ Edition ed., Industrial Press Inc. New York. 
Thai, H.T. and Choi, D.H. (2013). Efficient Higher-Order Shear Deformation Theories for Bending and Free Vibration Analyses of Functionally Graded Plates. Archive of Applied Mechanics, 83(12), pp.1755-1771.

Todhunter. (1887). A History of The Theory of Elasticity. Nature, 3, pp.313 - 314.

Vlasov, V. (1957). Method of Initial Functions in Problems of Theory of Thick Plates and Shells. Proceedings $9^{\text {th }}$ of the International Congresses on Theoretical and Applied Mechanics. Brussels, 321.

Wu Z.J. (1987). Exact Solution of Orthotropic Simply-Supported Rectangular Plates under Arbitrary Loadings, MSc dissertation, Department of Mathematics and Mechanics, University of Hefei Technology, Hefei, China.

Wu, Z.J. and Wardenier, J. (1998). Further Investigation on the Exact Elasticity Solution for Anisotropic Thick Rectangular Plates. International Journal of Solids and Structures, 35(7-8), pp.747-758.

Wu, Z. J., Han C. and Niu Z. R. (2015). A 3D Exact Analysis of The Boundary Layer Effect of Asymmetric Piezoelectric Laminates with Electromechanical Coupling. International Journal of Solids and Structures, 72, pp.118-129.

Ye, J. Q. (2003). Laminated Composite Plates and Shells: 3D Modelling, Springer.

Ye, J.Q., Sheng, H.Y. and Qin, Q.H. (2004). A State Space Finite Element for Laminated Composites with Free Edges and Subjected To Transverse and In-Plane Loads. Computers \& Structures, 82(15-16), pp.1131-1141. 


\title{
STATE SPACE APPROACH WITH FEM FOR THE DETERMINATION OF STRUCTURAL BEHAVIOUR OF COMPOSITE PLATES
}

In this paper, state space approach (SSA) and finite element method (FEM) are used for the determination of structural behaviour of simply supported orthotropic composite plates under different types of loading. The results obtained by using SSA are compared with the numerical results from ABAQUS. The effect of the plate thickness on displacements and stresses is described quantitatively. The neutral plane of the plate, identified according to the values of the in-plane strains through the thickness direction, is shifted away from the middle plane.
\end{abstract}

Keywords: State space approach, Finite element method, Neutral plane, Composite plates.

\section{Introduction}

The increasing demand on the structures made of the composite materials in the various high performance applications led to the development of new methods that are suitable for the analysis and study of the structural and mechanical behaviour of the structures (Ye et al., 2004).

According to Reddy (2004) and Ghugal and Shimpi (2002), there are many approaches that were used for the analysis of the composite plates including classical plate theory (CPT) and various $2 \mathrm{D}$ shear deformation plate theories. These 2D plate theories have many assumptions and inconsistencies such as neglecting the normal strain through the thickness direction of a plate, plane stress constitutive relations are used with plane strain assumption, etc.

Although the researches in 2D theories provide a good predication of some global responses in thin plates and an initial understanding of the behaviour of the plates, these theories can give only a rough estimation for the interlaminar stresses through the thickness of a plate. The accuracy of the results decreases as the thickness of plate increases.

To overcome the limitations to the $2 \mathrm{D}$ solutions for plates, the $3 \mathrm{D}$ solutions that take into account the constitutive equations, the kinematic equations, and the stress equilibrium equations in 3D linear elasticity are prevailed. 3D solutions can detail the global and local responses of plates with accurate prediction on the structural behaviour (Han, 2014). Obviously, the accurate prediction for the behaviour of the composite material should be based on 3D rather than 2D approaches. One of the 3D plate theories is called state space approach (Wu et al, 2015). It provides accurate three-dimensional solutions that guarantee continuous transverse stress distributions across the thickness of the plates. The boundary conditions and the continuity at the interfaces are satisfied. Besides that, the state space method can give reasonable estimation to a full range of structural behaviour for various thicknesses from thin to very thick plates (Sheng and Ye, 2003).

The state space approach considers all displacement and transverse stress components as the primary state variables simultaneously. The boundary conditions on the top and the bottom surfaces are directly related to them. Bahar (1975) considered a state space setting for homogeneous and isotropic plates.

As a pioneering researcher in 3D elastic theory, Wu (1987) introduced SSA to a 3D thick plate analysis. Fan and Ye (1990) presented an exact solution based on the space state method for statics and dynamics of orthotropic thick plates with simply supported edges. All fundamental equations of three-dimensional elasticity can be exactly satisfied and the nine elastic constants for orthotropic materials can be considered. Besides that the approach extended by Fan and Ye can be applied to the buckling of a thick orthotropic plate. Likewise, Wu and Wardenier (1998) achieved an exact 3D elasticity solution for simply supported thick, orthotropic and rectangular plates subjected to arbitrary loading. In fact, they obtained a sixth-order differential equation governing the transverse displacement for the first time in comparison with the fourth-order differential equation that is used in CPT.

In the following investigation of this paper, the space state method as a powerful $3 \mathrm{D}$ analytical approach is still adopted based on the literature review above. Then, a finite element analysis, as a numerical method, will be adopted and its results will be assessed and compared with the analytical solutions. A few new more findings and results will be reported. 


\section{Governing Equations}

Consider an elastic homogenous orthotropic rectangular plate of length $a$, width $b$ and uniform thickness $h$, the stress-strain relation becomes:

$$
\left\{\begin{array}{c}
\sigma_{x} \\
\sigma_{y} \\
\sigma_{z} \\
\tau_{y z} \\
\tau_{x z} \\
\tau_{x y}
\end{array}\right\}=\left[\begin{array}{cccccc}
C_{11} & C_{12} & C_{13} & 0 & 0 & 0 \\
C_{21} & C_{22} & C_{23} & 0 & 0 & 0 \\
C_{31} & C_{32} & C_{33} & 0 & 0 & 0 \\
0 & 0 & 0 & C_{44} & 0 & 0 \\
0 & 0 & 0 & 0 & C_{55} & 0 \\
0 & 0 & 0 & 0 & 0 & C_{66}
\end{array}\right]\left\{\begin{array}{c}
\partial u / \partial x \\
\partial v / \partial y \\
\partial w / \partial z \\
\partial v / \partial z+\partial w / \partial y \\
\partial u / \partial z+\partial w / \partial x \\
\partial u / \partial y+\partial v / \partial x
\end{array}\right\}
$$

In equation (1)

$$
\begin{array}{rlrl}
C_{11} & =\frac{E_{1}\left(1-v_{23} v_{32}\right)}{Q} & C_{12} & =\frac{E_{1}\left(v_{21}+v_{31} v_{23}\right)}{Q} \\
C_{22} & =\frac{E_{2}\left(1-v_{13} v_{31}\right)}{Q} & C_{13} & =\frac{E_{1}\left(v_{31}+v_{21} v_{32}\right)}{Q} \\
C_{33} & =\frac{E_{3}\left(1-v_{12} v_{21}\right)}{Q} & C_{23}=\frac{E_{2}\left(v_{32}+v_{12} v_{31}\right)}{Q} \\
C_{44}=G_{23} & C_{55}=G_{31} \\
C_{66} & =G_{12} \\
Q & =1-v_{12} v_{21}-v_{23} v_{32}-v_{31} v_{13}-2 v_{12} v_{23} v_{31} & \\
\frac{v_{i j}}{E_{i}} & =\frac{v_{j i}}{E_{j}} \quad i, j=1,2,3
\end{array}
$$

Where $E_{1}, E_{2}$ and $E_{3}$ are the Young's moduli of the plate among the material coordinates. The subscripts 1,2 and 3 indicate fibre direction, transverse and perpendicular to the plate respectively. $G_{12}, G_{23}$ and $G_{13}$ are shear moduli with respect to 1-2, 2-3 and 1-3 planes respectively. $v_{12}, v_{23}$ and $v_{13}$ are the Poisson's ratios correspondingly. The three in-plane stresses $\sigma_{x}, \sigma_{y}$ and $\tau_{x y}$ are eliminated and solved from the expression of state variables, as shown in equation (6). Three displacements in $x-y-z$ directions are labelled with $u, v$ and $w$. The transverse stresses $\sigma_{z}, \tau_{x z}$ and $\tau_{y z}$ are solved with respect to the $z$ coordinate directly from the state equation which can be written as follows (Ye, 2003):

$$
\frac{\partial}{\partial z}\left\{\mathrm{~F}_{m n}(z)\right\}=\left[\mathrm{G}_{m n}\right]\left\{\mathrm{F}_{m n}(z)\right\}
$$

Herein, $\left\{\mathrm{F}_{m n}(z)\right\}=\left[u v \sigma_{z} \tau_{x z} \tau_{y z} w\right]^{T}$ is the state vector of the plate. By solving the equation (3):

$$
\left\{\mathrm{F}_{m n}(z)\right\}=\left[\mathrm{D}_{m n}\right]\left\{\mathrm{F}_{m n}(0)\right\}
$$

and $\left[\mathrm{D}_{m n}\right]=\exp \left\{\left[\mathrm{G}_{m n}\right] z\right\}$, the system state matrix 
Once the state vector containing the three displacements and the three transverse stresses has been found the three in-plane stresses in the $x-y$ plane can be calculated from equation (6).

$$
\left\{\begin{array}{l}
\sigma_{x} \\
\sigma_{y} \\
\tau_{x y}
\end{array}\right\}=\left[\begin{array}{cccccc}
-C_{2} \zeta & -C_{3} \eta & -C_{1} & 0 & 0 & 0 \\
-C_{3} \zeta & -C_{4} \eta & -C_{5} & 0 & 0 & 0 \\
C_{6} \eta & C_{6} \zeta & 0 & 0 & 0 & 0
\end{array}\right]\left\{\begin{array}{c}
u \\
v \\
\sigma_{z} \\
\tau_{x z} \\
\tau_{y z} \\
w
\end{array}\right\}
$$

In equations (5) and (6)

$$
\begin{aligned}
C_{1} & =-\frac{C_{12}}{C_{33}} & C_{2} & =C_{11}-\frac{C_{12}{ }^{2}}{C_{33}} \\
C_{3} & =C_{12}-\frac{C_{13} C_{23}}{C_{33}} & C_{4} & =C_{22}-\frac{C_{23}{ }^{2}}{C_{33}} \\
C_{5} & =-\frac{C_{23}}{C_{33}} & C_{6} & =C_{66} \\
C_{7} & =\frac{1}{C_{33}} & C_{7} & =\frac{1}{C_{55}} \\
C_{9} & =\frac{1}{C_{44}} & & \\
\zeta & =\frac{m \pi}{a} & \eta & =\frac{n \pi}{b}
\end{aligned}
$$

The boundaries conditions for the four sides of the plate are simply supported (Figure 1), then the following boundary condition should be satisfied:

$$
\begin{aligned}
& \sigma_{x}=v=w=0 \text { at } x=0, a \\
& \sigma_{y}=u=w=0 \text { at } y=0, b
\end{aligned}
$$

In order to satisfy the boundary conditions specified in equation (8), the following six state variables of the state vector can be expressed by:

$$
\begin{aligned}
u(x, y, z) & =\sum_{m=1} \sum_{n=1} U_{m n}(z) \cos (m \pi x / a) \sin (n \pi y / b) \\
v(x, y, z) & =\sum_{m=1} \sum_{n=1} V_{m n}(z) \sin (m \pi x / a) \cos (n \pi y / b) \\
w(x, y, z) & =\sum_{m=1} \sum_{n=1} W_{m n}(z) \sin (m \pi x / a) \sin (n \pi y / b)
\end{aligned}
$$




$$
\begin{aligned}
\tau_{x z}(x, y, z) & =\sum_{m=1} \sum_{n=1} X_{m n}(z) \cos (m \pi x / a) \sin (n \pi y / b) \\
\tau_{y z}(x, y, z) & =\sum_{m=1} \sum_{n=1} Y_{m n}(z) \sin (m \pi x / a) \cos (n \pi y / b) \\
\sigma_{z}(x, y, z) & =\sum_{m=1} \sum_{n=1} Z_{m n}(z) \sin (m \pi x / a) \sin (n \pi y / b)
\end{aligned}
$$

To satisfy the load conditions on the top and bottom surfaces of the plate, the external loads can be expanded into Fourier series. For example, if the top surface of the plate is subjected to an arbitrarily distributed pressure $q(x, y)$, and the state vectors on the top and bottom surfaces of the plate are respectively:

and

$$
\left\{\mathrm{F}_{m n}(h)\right\}^{T}=\left[\begin{array}{lllllll}
U_{m n}(h) & V_{m n}(h) & 0 & 0 & 0 & W_{m n}(h)
\end{array}\right]
$$

$$
\left\{\mathrm{F}_{m n}(0)\right\}=\left\{\begin{array}{c}
U_{m n}(0) \\
V_{m n}(0) \\
a b \int_{0}^{a} \int_{0}^{b} q(x, y) \sin (m \pi x / a) \sin (n \pi y / b) d x d y \\
0 \\
0 \\
W_{m n}(0)
\end{array}\right\}
$$

Further formulation simplification can be used if $q(x, y)=q$ is a constant, and

$$
\frac{4}{a b} \int_{0}^{a} \int_{0}^{b} q(x, y) \sin (m \pi x / a) \sin (n \pi y / b) d x d y= \begin{cases}0 & (m, n=2,4,6, \ldots \ldots) \\ \frac{-16 q}{m n \pi^{2}} & (m, n=1,3,5, \ldots \ldots)\end{cases}
$$

\section{Analysis and Results}

Two examples are analysed by using SSA and FEM and the results are compared.

\subsection{Example 1}

In this example, the geometry of the composite plate is $a=b$ and $h / a=0.1,0.2,0.3,0.4$ and 0.5 . Where $a$ is the length of the plate along $x$-axis, $b$ is the dimension of the plate along $y$-axis and $h$ is the thickness of the plate $(z$-axis) as shown in Figure 1.

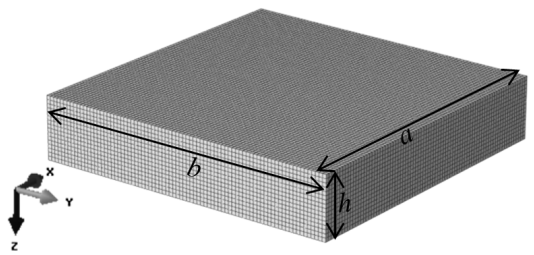

Fig.1. Geometry of a plate.

The following material properties are used in this example:

$$
\begin{aligned}
& E_{1}=10 E_{2}=10 E_{3} \\
& G_{12}=G_{13}=0.6 E_{3} \\
& G_{23}=0.5 E_{3} \\
& v_{12}=v_{13}=v_{23}=0.25
\end{aligned}
$$

The plate is simply-supported for all sides and the loading is an anti-symmetrical half single sine distributed out- of- plane load $\frac{q}{2} \sin \left(\frac{\pi x}{a}\right) \sin \left(\frac{\pi y}{b}\right)$. Hence, $Z_{\mathrm{mn}}(\mathrm{z})$ at the top $(z=0)$ and the bottom $(z=h)$ surfaces of the plate are equal to $-q / 2$ and $q / 2$ respectively. The numerical results are analysed by using ABAQUS and the results are 
compared with the analytical solution. As shown in Table I the results for the top and the bottom surfaces of the plate are the same with different sign because the loading condition is anti-symmetric.

\subsection{Parametric Studies}

In the example 1 , the effects of $\mathrm{BC}$ sensitivity and thickness to width ratios of the plate on the analytical results are systematically discussed, together with numerical precision considerations under different element types and mesh sizes in FEM comparison.

\section{- Element types}

According to Tables II and III, the solid elements have a better agreement with the analytical values than that of the shell elements especially for the displacements values. In solid elements, the most suitable element that gives minimum relative errors in comparison with the analytical solution is C3D20. 
Table II. Relative errors for solid elements at $z=h$ for $h / a=0.2$

\begin{tabular}{|c|c|c|c|c|c|c|c|c|c|}
\hline & \multirow{5}{*}{ SSA } & \multicolumn{8}{|c|}{ FEM - Solid Elements } \\
\hline & & \multicolumn{2}{|c|}{ C3D8R } & \multicolumn{2}{|c|}{ C3D8 } & \multicolumn{2}{|c|}{ C3D20R } & \multicolumn{2}{|c|}{ C3D20 } \\
\hline & & \multicolumn{8}{|c|}{ Simpson } \\
\hline & & \multicolumn{8}{|c|}{3 Points } \\
\hline & & Values & $\begin{array}{c}\text { Relative } \\
\text { Error } \\
(\%)\end{array}$ & Values & $\begin{array}{c}\text { Relative } \\
\text { Error } \\
(\%)\end{array}$ & Values & $\begin{array}{c}\text { Relative } \\
\text { Error } \\
(\%)\end{array}$ & Values & $\begin{array}{c}\text { Relative } \\
\text { Error } \\
(\%)\end{array}$ \\
\hline $\boldsymbol{u} \cdot \boldsymbol{E}_{3} / \boldsymbol{q} \boldsymbol{h}$ at $x=a / 2$ and $y=b / 2$ & -1.74625 & -1.87304 & -7.3 & -1.86204 & -6.6 & -1.68498 & 3.5 & -1.79068 & -2.5 \\
\hline $\boldsymbol{v} \cdot \boldsymbol{E}_{3} / \boldsymbol{q} \boldsymbol{h}$ at $x=a / 2$ and $y=b / 2$ & -2.42681 & -2.71048 & -11.7 & -2.55635 & -5.3 & -2.07370 & 14.6 & -2.27685 & 6.2 \\
\hline$\sigma_{z} / \boldsymbol{q}$ at $x=a / 2$ and $y=b / 2$ & 0.50000 & 0.49385 & 1.2 & 0.48491 & 3.0 & 0.50197 & -0.4 & 0.50299 & -0.6 \\
\hline$\tau_{x z} / q$ at $x=a / 2$ and $y=b / 2$ & 0.00000 & 0.00000 & 0.0 & 0.00000 & 0.0 & 0.00000 & 0.0 & 0.00000 & 0.0 \\
\hline$\overline{\tau_{y} / q} / q$ at $x=a / 2$ and $y=b / 2$ & 0.00000 & 0.00000 & 0.0 & 0.00000 & 0.0 & 0.00000 & 0.0 & 0.00000 & 0.0 \\
\hline $\boldsymbol{w} \cdot \boldsymbol{E}_{3} / \boldsymbol{q} \boldsymbol{h}$ at $x=a / 2$ and $y=b / 2$ & 8.82332 & 9.31376 & -5.6 & 9.30444 & -5.5 & 9.29750 & -5.4 & 9.29749 & -5.4 \\
\hline$\sigma_{x} / q$ at $x=a / 2$ and $y=b / 2$ & 11.58183 & 11.11267 & 4.1 & 11.43132 & 1.3 & 12.15463 & -4.9 & 12.17926 & $\overline{-5.2}$ \\
\hline$\sigma_{y} / \boldsymbol{q}$ at $x=a / 2$ and $y=b / 2$ & 1.93935 & 1.86762 & 3.7 & 1.89783 & 2.1 & 2.00208 & -3.2 & 2.00374 & -3.3 \\
\hline$\tau_{x y} / q$ near the edge & -1.57320 & -1.11226 & 29.3 & -1.22090 & 22.4 & -1.21522 & 22.8 & -1.21764 & 22.6 \\
\hline
\end{tabular}

Table III. Relative errors for shell elements at $z=h$ for $h / a=0.2$.

\begin{tabular}{|c|c|c|c|c|c|c|c|c|c|c|c|}
\hline & \multirow{5}{*}{ SSA } & \multicolumn{10}{|c|}{ FEM - Shell Elements } \\
\hline & & \multicolumn{6}{|c|}{ S8R } & \multicolumn{2}{|c|}{ S4 } & \multicolumn{2}{|c|}{ S4R5 } \\
\hline & & \multicolumn{4}{|c|}{ Gauss } & \multirow{2}{*}{\multicolumn{2}{|c|}{$\begin{array}{c}\text { Simpson } \\
\text { 3,5 Points }\end{array}$}} & \multicolumn{4}{|c|}{ Simpson } \\
\hline & & \multicolumn{2}{|c|}{4 Points } & \multicolumn{2}{|c|}{5 Points } & & & \multicolumn{4}{|c|}{3 Points } \\
\hline & & Values & $\begin{array}{c}\text { Relative } \\
\text { Error } \\
(\%) \\
\end{array}$ & Values & $\begin{array}{c}\text { Relative } \\
\text { Error } \\
(\%) \\
\end{array}$ & Values & $\begin{array}{c}\text { Relative } \\
\text { Error } \\
(\%) \\
\end{array}$ & Values & $\begin{array}{c}\text { Relative } \\
\text { Error } \\
(\%) \\
\end{array}$ & Values & $\begin{array}{c}\text { Relative } \\
\text { Error (\%) }\end{array}$ \\
\hline u. $\boldsymbol{E}_{3} / \boldsymbol{q} \boldsymbol{h}$ at $x=a / 2$ and $y=b / 2$ & -1.74625 & - & - & - & - & - & - & - & - & - & - \\
\hline $\boldsymbol{v} \cdot \boldsymbol{E}_{3} / \boldsymbol{q} \boldsymbol{h}$ at $x=a / 2$ and $y=b / 2$ & -2.42681 & - & - & - & - & - & - & - & - & - & - \\
\hline $\boldsymbol{\sigma}_{z} / \boldsymbol{q}$ at $x=a / 2$ and $y=b / 2$ & 0.50000 & - & - & - & - & - & - & - & - & - & - \\
\hline $\boldsymbol{\tau}_{x z} / \boldsymbol{q}$ at $x=a / 2$ and $y=b / 2$ & 0.00000 & 0.00000 & 0.0 & 0.00000 & 0.0 & 0.00000 & 0.0 & 0.00000 & 0.0 & 0.00000 & 0.0 \\
\hline $\boldsymbol{\tau}_{y z} / \boldsymbol{q}$ at $x=a / 2$ and $y=b / 2$ & 0.00000 & 0.00000 & 0.0 & 0.00000 & 0.0 & 0.00000 & 0.0 & 0.00000 & 0.0 & 0.00000 & 0.0 \\
\hline $\boldsymbol{w} \cdot \boldsymbol{E}_{3} / \boldsymbol{q} \boldsymbol{h}$ at $x=a / 2$ and $y=b / 2$ & 8.82332 & 9.47645 & -7.4 & 9.47645 & -7.4 & 9.47613 & -7.4 & 9.47546 & -7.4 & 9.47645 & -7.4 \\
\hline $\boldsymbol{\sigma}_{x} / \boldsymbol{q}$ at $x=a / 2$ and $y=b / 2$ & 11.58183 & 9.47251 & 18.2 & 9.96799 & 13.9 & 11.00879 & 4.9 & 11.00304 & 5.0 & 11.00001 & 5.0 \\
\hline $\boldsymbol{\sigma}_{y} / \boldsymbol{q}$ at $x=a / 2$ and $y=b / 2$ & 1.93935 & 1.58869 & 18.1 & 1.67179 & 13.8 & 1.84623 & 4.8 & 1.84544 & 4.8 & 1.84488 & 4.9 \\
\hline$\tau_{x y} / q$ near the edge & -1.57320 & -0.95922 & 39.0 & -1.00940 & 35.8 & -1.11613 & 29.1 & -1.11382 & 29.2 & -1.11391 & 29.2 \\
\hline
\end{tabular}

- $\quad$ Mesh sizes

Three mesh sizes are used for the modelling in this paper. The first one is $0.25 \times 0.25$, the second is $0.125 \times 0.125$ and the last one is $0.0625 \times 0.0625$. Mesh sensitivity test was taken to check which mesh size would be more appropriate for particular cases. As shown in Table IV and Figure 2, when the mesh sizes of the elements decrease, its relative error with respect to the exact solution will be smaller and the results will be more accurate. For this reason, the mesh 3 will be used in the current FEM analysis. Due to anti-symmetric half single sine distributed out -of- plane loading, the numerical results for the out-of- plane stresses $\sigma_{z}$ from ABAQUS should be equal to $-q / 2$ or $q / 2$ on the top and bottom surfaces of the plate. These values can be used to confirm if the numerical results are true or not. 


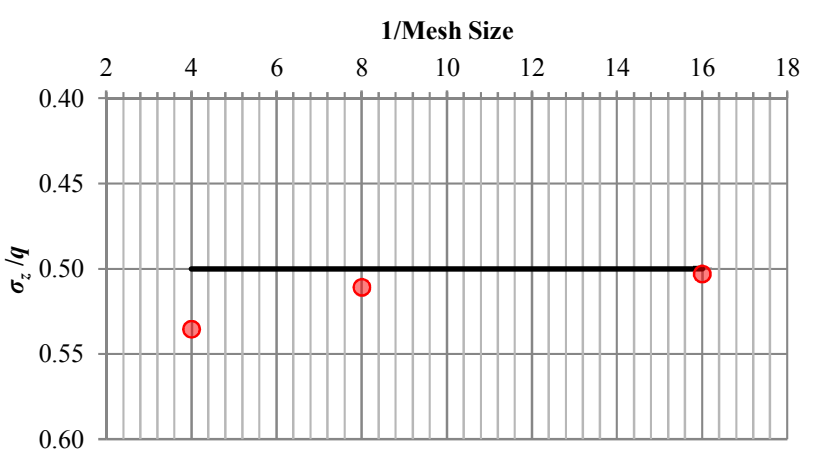

- FEM $\longrightarrow$ SSA

Fig.2. Different mesh sizes results for $\sigma_{z} / q$ at $z=h$ for $h / a=0.2$.

- $\quad B C$ sensitivity

The boundary conditions play a very important role in getting an accurate FE results. For simply supported edges, the ABAQUS gives different options to select an appropriate BC. To make sure which option should be used, Table $\mathrm{V}$ shows the different types of options in the simply supported edges. From the table the values of the displacements and the stresses are nearly equal to the exact solutions in case of U3 is equal to zero only. Because of this, U3 boundary condition is chosen for the following analysis. Figure 3 shows that the BC(3) is the most accurate option comparing to the other options, and the results get closer to the exact solution.

Table V. The effect of BC sensitivity on the displacements and stresses at $z=h$ for $h / a=0.2$.

\begin{tabular}{|c|c|c|c|c|}
\hline & \multirow{3}{*}{ SSA } & \multicolumn{3}{|c|}{ FEM } \\
\hline & & BC (1) & BC (2) & BC (3) \\
\hline & & $\begin{array}{l}\mathrm{U} 2=\mathrm{U} 3=0(\mathrm{X}) \\
\mathrm{U} 1=\mathrm{U} 3=0(\mathrm{Y})\end{array}$ & $\mathbf{U} \mathbf{1}=\mathbf{U} \mathbf{2}=\mathbf{U} \mathbf{3}=\mathbf{0}$ & $\mathbf{U} \mathbf{3}=\mathbf{0}$ \\
\hline u. $\boldsymbol{E}_{3} / \boldsymbol{q} \boldsymbol{h}$ at $x=a / 2$ and $y=b / 2$ & -1.74625 & -0.50408 & -0.50079 & -1.79068 \\
\hline v. $\boldsymbol{E}_{3} / \boldsymbol{q} \boldsymbol{h}$ at $x=a / 2$ and $y=b / 2$ & -2.42681 & -1.09923 & -1.09289 & -2.27685 \\
\hline $\boldsymbol{\sigma}_{z} / \boldsymbol{q}$ at $x=a / 2$ and $y=b / 2$ & 0.50000 & 0.89458 & 0.89805 & 0.50299 \\
\hline $\boldsymbol{\tau}_{x z} / \boldsymbol{q}$ at $x=a / 2$ and $y=b / 2$ & 0.00000 & 0.00000 & 0.00000 & 0.00000 \\
\hline $\boldsymbol{\tau}_{y z} / \boldsymbol{q}$ at $x=a / 2$ and $y=b / 2$ & 0.00000 & 0.00000 & 0.00000 & 0.00000 \\
\hline $\boldsymbol{w} \cdot \boldsymbol{E}_{3} / \boldsymbol{q} \boldsymbol{h}$ at $x=a / 2$ and $y=b / 2$ & 8.82332 & 5.03543 & 5.00869 & 9.29749 \\
\hline $\boldsymbol{\sigma}_{x} / \boldsymbol{q}$ at $x=a / 2$ and $y=b / 2$ & 11.58183 & 16.23791 & 15.97628 & 12.17926 \\
\hline$\sigma_{y} / \boldsymbol{q}$ at $x=a / 2$ and $y=b / 2$ & 1.93935 & 3.91500 & 3.87508 & 2.00374 \\
\hline$\tau_{x y} / q$ near the edge & -1.57320 & 0.48985 & 0.51068 & -1.21764 \\
\hline
\end{tabular}


- $\quad$ Thickness to width ratios

One of the advantages for using the state space approach is the capability of this approach to get an exact solution. Figure 4 shows the effect of the thickness to width ratios $(h / a)$ on the in-plane stress $\sigma_{x}$. The behaviour of the stresses through the thickness is nonlinear as $h / a$ increases.

The non-linear behaviour of the stress distribution through the thickness is observed in Figure 5. Since the SSA describes the exact behaviour of the plate, this figure shows that the linear strain distribution assumption through the thickness direction in CPT is inappropriate.

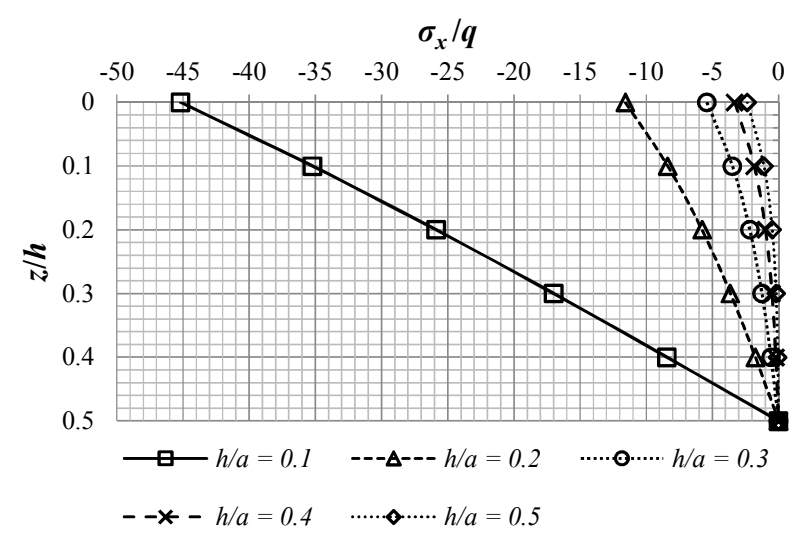

Fig.4. The effect of different $h / a$ on the in-plane $\left(\sigma_{x} / q\right)$ through the thickness.

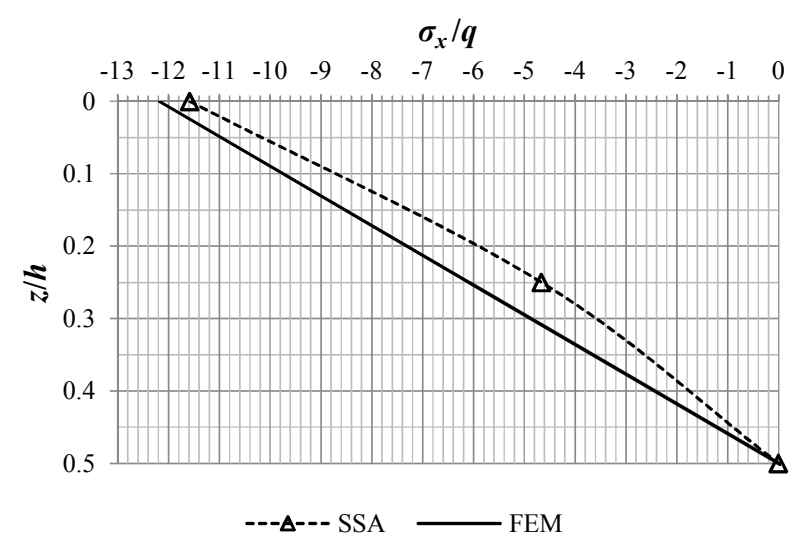

Fig.5. In-plane stress $\left(\sigma_{x} / q\right)$ distribution through the thickness for $h / a=0.2$. 


\subsection{Example 2}

In this example, the geometry, material properties and the boundary conditions of the plate are exactly the same as Example 1. The only difference with example 1 is that the loadings on top surface of the plate is uniformly distributed $q(x, y)=q$ and the loadings on the bottom surface of the plate is nill.

Table VI shows the displacements and stresses on the top and bottom surfaces in the example 2. Also, the stress distributions through the thickness of the plate are presented in Figure 6. The nonlinear behaviour for the displacement and the stress are clearly noticed. Accordingly, the location of the neutral surface will be shifted away (downward or upward) from the middle plane of the plate depending on the direction of the load.

\begin{tabular}{|c|c|c|}
\hline \multirow{2}{*}{$\boldsymbol{u} \cdot \boldsymbol{E}_{3} / \boldsymbol{q} \boldsymbol{h}$ at $x=a / 2$ and $y=b / 2$} & Top & 2.88299 \\
\cline { 2 - 3 } & Bottom & -2.81915 \\
\hline \multirow{2}{*}{$\boldsymbol{v} \cdot \boldsymbol{E}_{3} / \boldsymbol{q} \boldsymbol{h}$ at $x=a / 2$ and $y=b / 2$} & Top & 4.22879 \\
\cline { 2 - 3 } & Bottom & -4.41992 \\
\hline \multirow{2}{*}{$\boldsymbol{w} \boldsymbol{E}_{3} / \boldsymbol{q} \boldsymbol{h}$ at $x=a / 2$ and $y=b / 2$} & Top & 13.72184 \\
\cline { 2 - 3 } & Bottom & 13.22557 \\
\hline \multirow{2}{*}{$\sigma_{x} / \boldsymbol{q}$ at $x=a / 2$ and $y=b / 2$} & Top & -17.35693 \\
\cline { 2 - 3 } & Bottom & 17.39349 \\
\hline \multirow{2}{*}{$\sigma_{y} / \boldsymbol{q}$ at $x=a / 2$ and $y=b / 2$} & Top & -2.47664 \\
\cline { 2 - 3 } & Bottom & 2.42128 \\
\hline \hline \multirow{2}{*}{$\tau_{x y} / \boldsymbol{q}$ near the edge } & Top & 3.50882 \\
\cline { 2 - 3 } & Bottom & -3.07349 \\
\hline
\end{tabular}

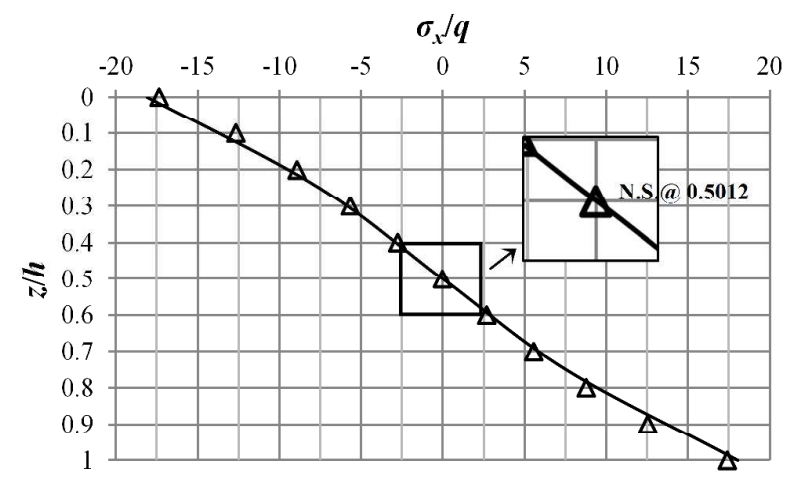

$\Delta \quad$ SSA - HEM

Fig.6. Stress $\left(\sigma_{r} / q\right)$ distribution through the thickness for $h / a=0.2$.

\section{CONCLUSIONS}

An analytical investigation has been carried out for a simply supported rectangular plate with two different loading conditions by using 3D SSA and finite element method. The following main conclusions can be drawn:

- As the thickness of the plate increases, the 2D theories give inaccurate results compared to the 3D SSA.

- The neutral surface of the plate is shifted away from the middle plane according to the values of the in-plane strains.

- Among the different types of elements used in FEM, the solid element gives better result, especially, for the displacements. 


\section{References}

Bahar, L.Y. (1975). A State Space Approach to Elasticity. Journal of The Franklin Institute, pp.33-41.

Fan, J. and Ye, J. (1990). An Exact Solution for the Statics and Dynamics of Laminated Thick Plates with Orthotropic Layers. International Journal of Solids and Structures, 26(7), pp.655-662.

Ghugal Y. M. and Shimpi R. P. (2002). A Review of Refined Shear Deformation Theories of Isotropic and Anisotropic Laminated Plates. Journal of Reinforced Plastics and Composites, 21(9), p.775.

Han, C. (2014). 3D State Space Analysis and Free-Edge Effect of Piezoelectric Laminated Thick Plates. University of Manchester.

Reddy, J. N. (2004). Mechanics of Laminated Composite Plates and Shells: Theory and Analysis, CRC press.

Sheng, H.Y. and Ye, J.Q. (2003). A Three-Dimensional State Space Finite Element Solution for Laminated Composite Cylindrical Shells. Computer Methods in Applied Mechanics and Engineering, 192(22-24), pp.2441-2459.

Wu Z.J. (1987). Exact solution of orthotropic simply-supported rectangular plates under arbitrary loadings, MSc dissertation, Department of Mathematics and Mechanics, University of Hefei Technology, Hefei, China.

Wu, Z.J. and Wardenier, J. (1998). Further Investigation on the Exact Elasticity Solution for Anisotropic Thick Rectangular Plates. International Journal of Solids and Structures, 35(7-8), pp.747-758.

Wu, Z. J., Han C. and Niu Z. R. (2015). A 3D exact analysis of the boundary layer effect of asymmetric piezoelectric laminates with electromechanical coupling. International Journal of Solids and Structures, 72, pp.118-129.YE, J. Q. (2003). Laminated Composite Plates and Shells: 3D Modelling, Springer.

Ye, J.Q., Sheng, H.Y. and Qin, Q.H. (2004). A State Space Finite Element for Laminated Composites with Free Edges and Subjected To Transverse and In-Plane Loads. Computers \& Structures, 82(15-16), pp.1131-1141. 